\title{
Postopki in težave terenskega dela pri ugotavljanju navzočnosti ka- rantenskih in drugih škodljivih organizmov s kontrolnimi pastmi v gozdovih Slovenije
}

\section{Peter SMOLNIKAR*}

\section{Uvod}

Gozd in drevesa odločilno vplivajo na kakovost življenja v nekem okolju. Vse svoje funkcije gozdovi in posamezna drevesa lahko v polnosti opravljajo le, če so vitalni. V spreminjajočem podnebju drevesa v slovenskih gozdovih čedalje bolj ogrožajo ekstremni vremenski dogodki in posledično namnožitve domačih škodljivih organizmov. Globalizacija in mednarodni trgovinski promet pa predstavljata veliko nevarnost vnosa invazivnih tujerodnih škodljivih organizmov na nova ozemlja, tudi k nam.

Invazivni tujerodni škodljivi organizmi so tisti, ki lahko povzročijo gospodarsko, ekološko in družbeno škodo. Evropska Komisija je pripravila sezname škodljivih organizmov (ک̌O) rastlin za ozemlje Unije (Delegirana ..., 2019; Izvedbena ..., 2019). Navzočnost določenih ŠO rastlin na ozemlju Unije je potrebno spremljati in tako je Slovenija, kot država članica evropske skupnosti, po Uredbi 2016/2031 (Uredba..., 2016) dolžna vsako leto spremljati in poročati o navzočnosti ali odsotnosti določenih karantenskih in drugih ŠO iz seznamov uredb (Delegirana ..., 2019; Izvedbena ..., 2019). Za poročanje komisiji EU je v Sloveniji odgovorna Uprava za varno hrano veterinarstvo in varstvo rastlin (UVHVVR). Po javnem pooblastilu UVHVVR navzočnost nekaterih ŠO, ki predstavljajo nevarnost za gozdove, ugotavlja tudi Gozdarski inštitut Slovenije (GIS) - Laboratorij za varstvo gozdov (LVG).

Spremljanje $\mathrm{z}$ namenom ugotavljanja navzočnosti karantenskih in drugih ŠO rastlin $v$ gozdovih poteka $\mathrm{v}$ okviru t.i. programov preiskav. V letu 2020 je GIS s svojimi koordinatorji sodeloval pri izvedbi enajstih programov preiskav (Program..., 2020). Navzočnost S̆O običajno ugotavljamo na dva načina, z vizualnim pregledovanjem sestojev gostiteljskih dreves ter s spremljanjem ulova $\mathrm{v}$ pasti, opremljene $\mathrm{z}$ vabami (kontrolne pasti). Aktivnosti prednostno izvajamo na točkah, kjer je ob morebitnem vnosu verjetnost za detekcijo iskanih ŠO največja, (npr. v okolici skladišč lesa, žag, pristanišč in letališč, ob glavnih transportnih poteh, ...), ter v sestojih z visokim deležem lesnih zalog gostiteljev iskanih ŠO.

V prispevku bomo osvetlili težave, ki se nam lahko pripetijo pri izvajanju terenskega dela v sklopu programov preiskav, natančneje pri nameščanju kontrolnih pasti in odvzemu vzorcev.

\section{Priprava na teren}

Prvi korak ugotavljanja navzočnosti ŠO rastlin v gozdovih je načrtovanje potrebnega števila vizualnih pregledov, pasti in vzorcev, da dosežemo zadostno pokritost območja in zanesljivost (reprezentativnost) vzorčenja. Slovenija je za potrebe ugotavljanja navzočnosti
ŠO rastlin v okviru programov preiskav razdeljena na pet območij, znotraj katerih se določijo natančno št. vizualnih pregledov, št. kontrolnih pasti in št. odvzetih vzorcev. Načrtovanju sledi nakup materiala, potrebnega za postavitev kontrolnih pasti (pasti, ogrodij, vrstno specifičnih feromonov, kairomonov, lončkov, čopičev, vrvic, ...). Na nivoju EU so v pripravi protokoli, ki bodo omogočali poenoten pristop k izvajanju programov preiskav za posamezne S̆O.

$\mathrm{V}$ drugem koraku s pomočjo sestojne karte Zavoda za gozdove Slovenije (ZGS) in podatkov o lokacijah lesnih in gozdarskih podjetij Statističnega urada Republike Slovenije (SURS) izberemo lokacije, primerne za postavitev pasti, ki morajo ustrezati določenim kriterijem (gostiteljski sestoj, ekspozicija, bližina potencialnih točk vnosa). Naše predlagane lokacije pošljemo v pregled revirnim gozdarjem (ZGS), ti pa nam podajo realno informacijo s terena o primernosti predlaganih lokacij (dostopnost, lastništvo, strinjanje lastnika, stanje sestoja, morebitne predvidene sečnje) in po potrebi predlagajo ustreznejšo znotraj meja svojega revirja.

Po dogovoru in potrditvi ustreznih lokacij in dobavi materiala začnemo nekaj dni pred nastopom obdobja aktivnosti odraslih osebkov posameznih S̆O (določen temperaturni prag in vsota efektivnih temperatur (stopinj dni)) s postavitvijo kontrolnih pasti.

\section{Delo na terenu - postavitev pasti}

Pri izvajanju programov preiskav uporabljamo različne tipe pasti. Za ulov hroščev brezovega krasnika (Agrilus anxius) in jesenovega krasnika (A.planipennis) uporabljamo pasti $\mathrm{v}$ obliki tristrane prizme vijolične ali zelene barve in z lepljivo zunanjo površino. Pasti so opremljene z vabo (vaba za Agrilus planipennnis je feromon in kairomon, v primeru $A$. anxius pa uporabljamo le kairomon) in nameščene visoko v krošnji gostiteljskih dreves (jesen oz. breza) (Slika 1). Past je nameščena približno 30 dni v aktivnem obdobju odraslih osebkov (maj - julij). Po tem obdobju se jo demontira, zavije v vrečo, opremi z uradno nalepko in pošlje v Laboratorij za varstvo gozdov na GIS.

Za ugotavljanje navzočnosti neevropskih vrst kozličkov iz rodu Monochamus in spremljanje vektorjev borove ogorčice (Bursaphelenchus xylophilus), t.j. kozličkov iz rodu Monochamus, uporabljamo križne pasti z vabami (Slika 2). Pasti namestimo v krošnjo gostiteljskih dreves (iglavci). V primeru spremljanja vektorjev borove ogorčice pasti opremimo z zbirno posodico z rešetko, tako da ulov ostaja suh. Kontrolne pasti kontroliramo tedensko in še žive kozličke shranimo $\mathrm{v}$ lončke $\mathrm{z}$ omogočenim pretokom zraka, ki jih opremimo z uradno nalepko in dostavimo v LVG za morfološko analizo. Po 
determinaciji se jih pošlje naprej na Kmetijski inštitut Slovenije (KIS), kjer vektorje testirajo na prisotnost borove ogorčice. Kontrolne pasti za ugotavljanje navzočnosti neevropskih vrst kozličkov iz rodu Monochamus so opremljene z zaprto zbirno posodico, v kateri je nalit antifriz, ki deluje kot konzervans. Te pasti kontroliramo vsakih 30 dni, vsak vzorec opremimo z uradno nalepko in dostavimo v LVG za morfološko analizo ulova.

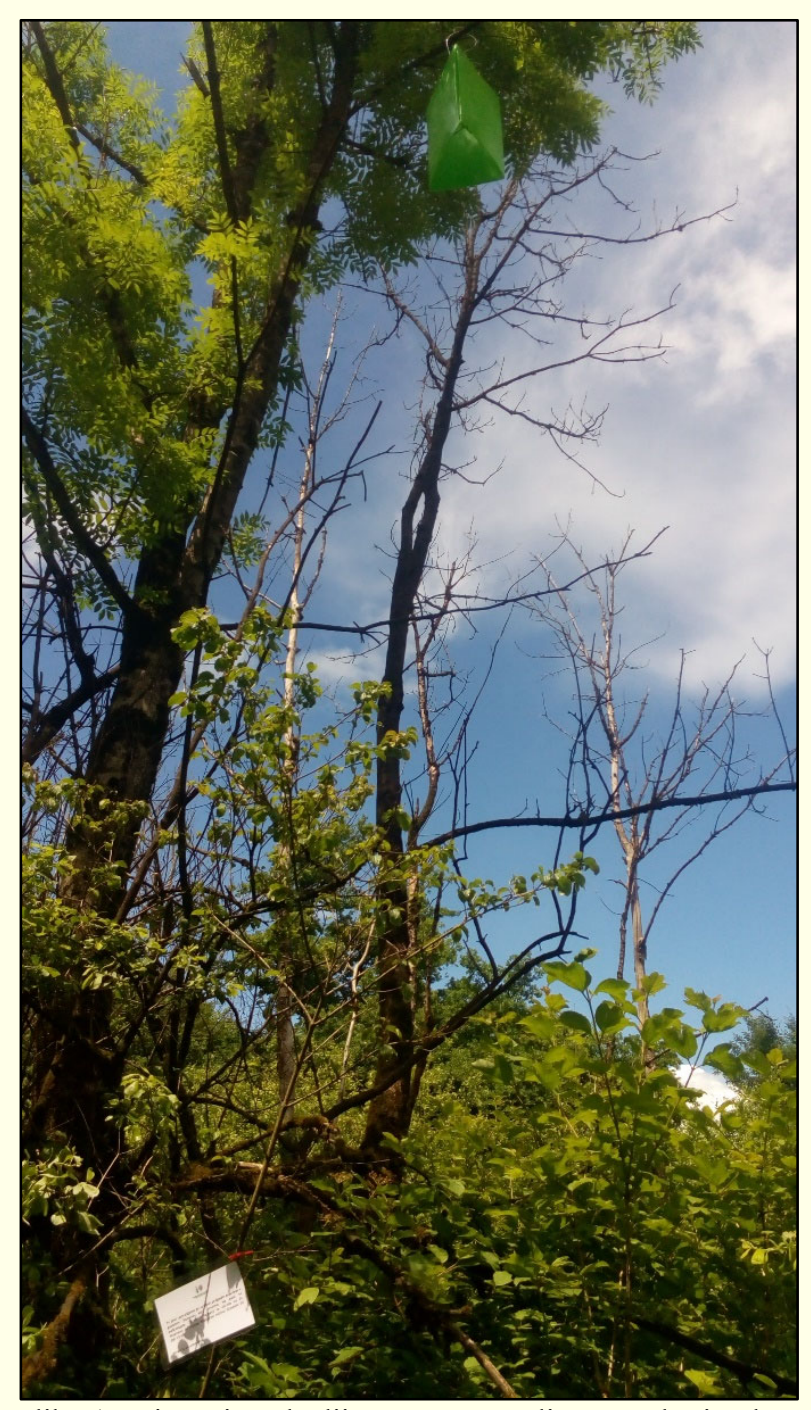

Slika 1: Prizmatična lepljiva past, opremljena $\mathrm{z}$ vabo in obešena v krošnjo jesena Fraxinus excelsior, je namenjena ugotavljanju navzočnosti jesenovega krasnika, (Agrilus planipen$n i s)$. Past je opremljena z obvestilom, ki vsebuje informacijo o namenu postavitve, kontaktnimi podatki odgovorne osebe in logotipom GIS (foto P. Smolnikar, GIS)

Za spremljanje azijskega ambrozijskega podlubnika (Xylosandrus crassiusculus) uporabljamo režaste pasti tipa Theysohn, opremljene z vabo - etanol, ki učinkuje kot kairomon. Pasti postavimo cca. 1,5 m od tal v gozdne sestoje $z$ velikim deležem gostiteljskih rastlin (številni listavci) in v bližini nasadov sadnega drevja. Pasti praznimo vsakih $14 \mathrm{dni}$. Ulov v posamezni pasti stresemo v plastičen lonček in ga zalijemo s 70\% etanolom, lonček opremimo $\mathrm{z}$ uradno nalepko in dostavimo $\mathrm{V}$ LVG.

Za ulov vektorjev glive, ki povzroča borov smolasti rak (Fusarium circinatum) uporabljamo režaste pasti tipa Theysohn, opremljene z ustreznimi feromoni in kairomoni (Tomowit, Sexowit ter mešanica etanola in $\alpha$ pinena). Kontrolne pasti postavimo $\mathrm{v}$ bližino borovih sestojev in jih praznimo vsakih 14 dni. Pri odvzemu vzorca moramo delo opravljati sterilno. Ulov s pomočjo sterilnega čopiča stresemo v sterilen lonček, ki ga opremimo z uradno nalepko. Vzorce v čim krajšem času dostavimo v LVG, kjer jih shranimo v zamrzovalnik do izvedbe analize.

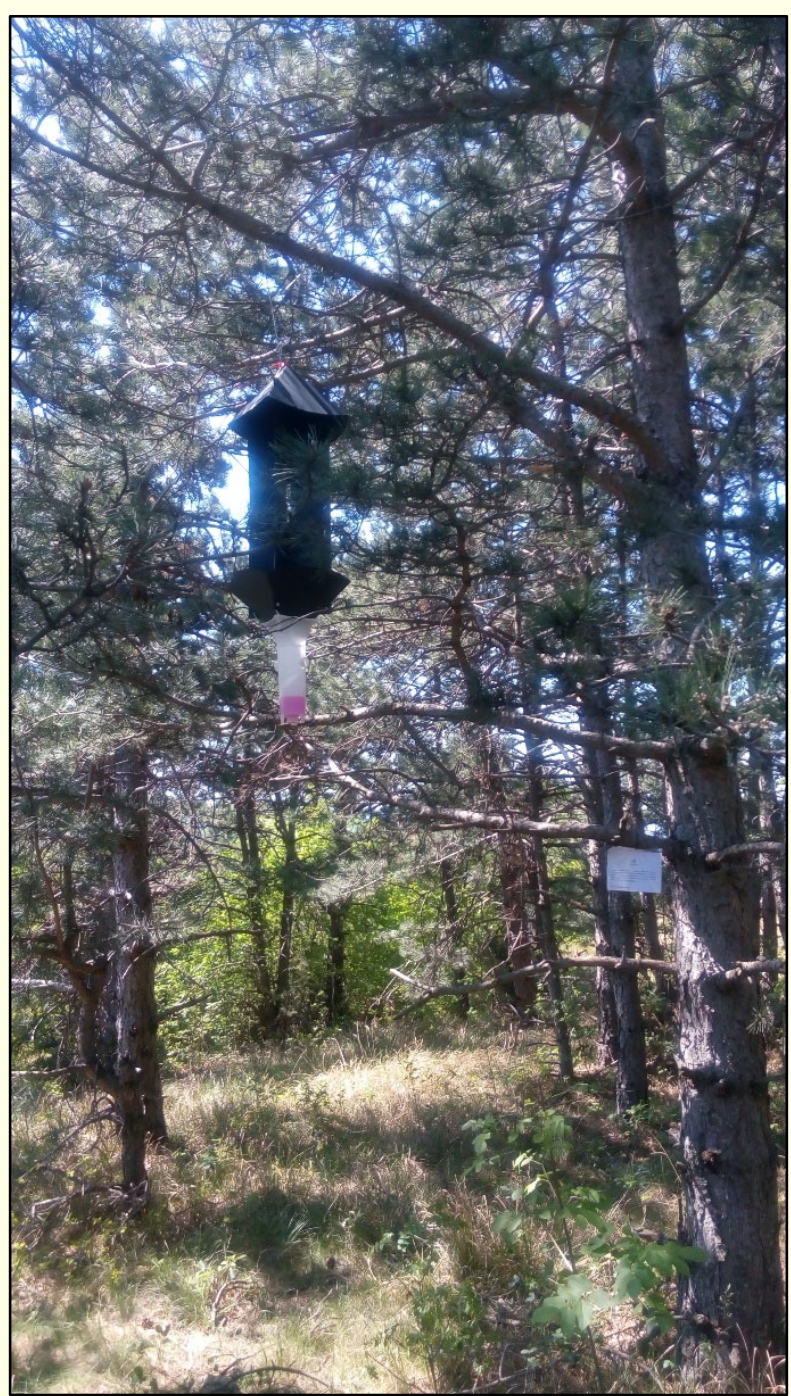

Slika 2: Križna past, ki jo uporabljamo za lovljenje neevropskih vrst kozličkov iz rodu Monochamus. Zbirna posoda je zatesnjena in napolnjena s konzervansom (npr. antifrizom). Enaka past se uporablja tudi za ulov vektorjev borove ogorčice, t.j. hroščev iz rodu Monochamus, z razliko, da je gre pri slednjem za suhi ulov, t.j. zbirna posoda je prazna in je omogočen odtok vode. Past je opremljena z obvestilom, ki vsebuje informacijo o namenu postavitve, kontaktnimi podatki odgovorne osebe in logotipom GIS (foto: P. Smolnikar, GIS)

S pastmi ugotavljamo tudi navzočnost bolezni tisočerih rakov, ki jo povzroča gliva Geosmithia morbida, oz. vektorja te glive, t.j. orehovega vejnega lubadarja (Pityophthorus juglandis). Kontrolne pasti opremimo $\mathrm{s}$ feromonskimi vabami za orehovega vejnega lubadarja in jih namestimo v krošnjo oreha (Juglans spp.). Ulov iz pasti pretresemo v lonček in zalijemo s 70\% etanolom, opremimo $\mathrm{z}$ uradno nalepko in pošljemo $\mathrm{v}$ LVG, kjer vzorce shranimo v hladilniku do analize. 
Kadar delamo s potencialno okuženim rastlinskim materialom (možnost okužbe s fitopatogenimi glivami), vse orodje pred in po vsaki uporabi obvezno razkužimo, da preprečimo prenos bolezni na zdrave rastline.

\section{Obseg težav}

V aktivnosti programov preiskav na GIS (vizualni pregledi, odvzem vzorcev s sumom na prisotnost karantenskih in drugih ŠO rastlin, postavitev kontrolnih pasti in zbiranje vzorcev iz njih) je bilo v letu 2020 neposredno vključenih 10 oseb, posredno pa še nekaj več. V okviru programov preiskav smo v letu 2020 skupno opravili 274 vizualnih pregledov rastlin na skoraj 600 ha površin, v sklopu katerih je bilo odvzetih 83 vzorcev s sumom na določen ŠO. Postavili smo 97 kontrolnih pasti, s katerih smo pridobili 231 vzorcev za nadaljnje analize.

Pri takšni količini pasti in vizualnih pregledov je obseg terenskega dela velik in občasno prihaja tudi do težav na terenu.

V prvo skupino težav (1-8) sodijo tiste, katerih vzrok so zunanji dejavniki, na katere nimamo neposrednega vpliva:

1) Pri načrtovanju lokacij so nam v veliko pomoč sestojne karte ZGS, pri tem pa se vseeno (če se ne posvetujemo z revirnim gozdarjem), lahko zgodi, da v izbranem sestoju ni gostiteljskih dreves (zastarela sestojna karta, posek ali napaka v podatkovni bazi šifranta drevesne vrste).

2) Lokacija za postavitev pasti je neprimerna oz. nedosegljiva, težavno je nameščanje pasti v drevesne krošnje v zelo gostih sestojih.

3) Pri dostopu do lokacij, ki so daleč od regionalnih cest, problem predstavljajo gozdne ceste s trajnimi zaporami (rampe) in začasne zapore, ki niso javno dostopno objavljene (npr. postavitev žičnice ali rekonstrukcija brez urejenega obvoza).

4) Na poti se prevozno sredstvo lahko pokvari.

5) Vremenske napovedi ne držijo.

6) Vandalizem - namerne poškodbe pasti, kraja feromonov in pasti (Slika 3).

7) Poškodbe pasti zaradi naravnih dejavnikov (močan veter, divjad, živina) (Slika 4).

8) Past namestimo na mesto (drevo), kjer bo potekala sanitarna ali še ne odkazana sečnja.

Za drugo skupino težav (A-E) smo soodgovorni tudi fitosanitarni pregledniki sami:

A) Pozabljivost (orodje in potrebni material ostanejo na sedežu podjetja).

B) Nepazljivost in izgubljeni material (padec iz žepa, veter odpihne vrečko s feromoni, tekočina (npr. etanol) se polije, vrv za pritrditev pasti se zatakne v krošnji in pretrga, ...).

C) Poškodbe prevoznega sredstva (predrta pnevmatika) ali obtičanje na terenu (tudi zaradi praznega akumulatorja ali rezervoarja za gorivo!).

D) Prevoz slepih potnikov (Slika 5).

E) Utrujenost.

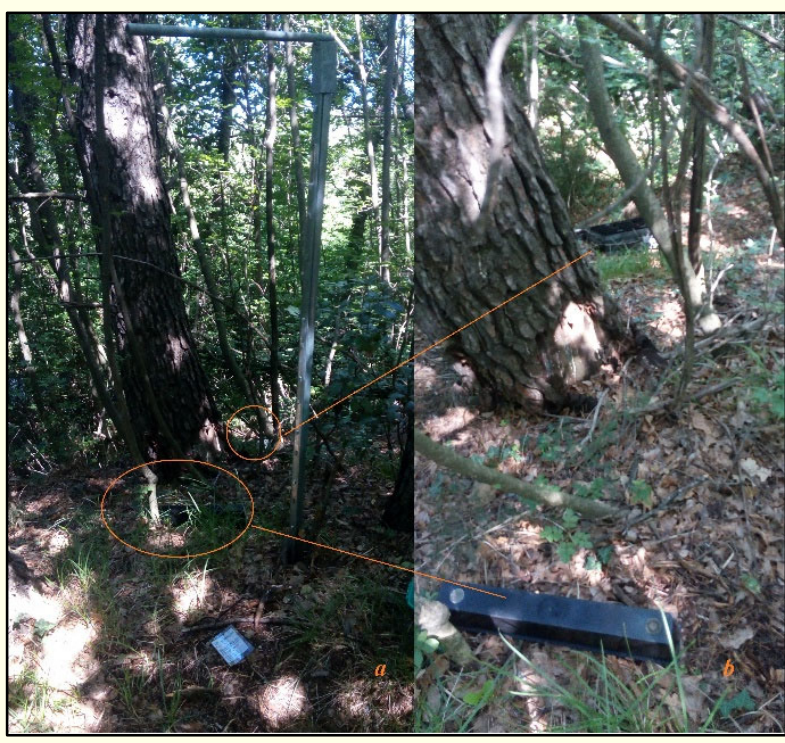

Slika 3: Razdrta (uničena) režasta past tipa Theysohn, namenjena za spremljanje vektorjev glive Fusarium circinatum, ki povzroča borov smolasti rak, je posledica vandalizma $(\mathrm{a}, \mathrm{b})$ (foto: P. Smolnikar, GIS)

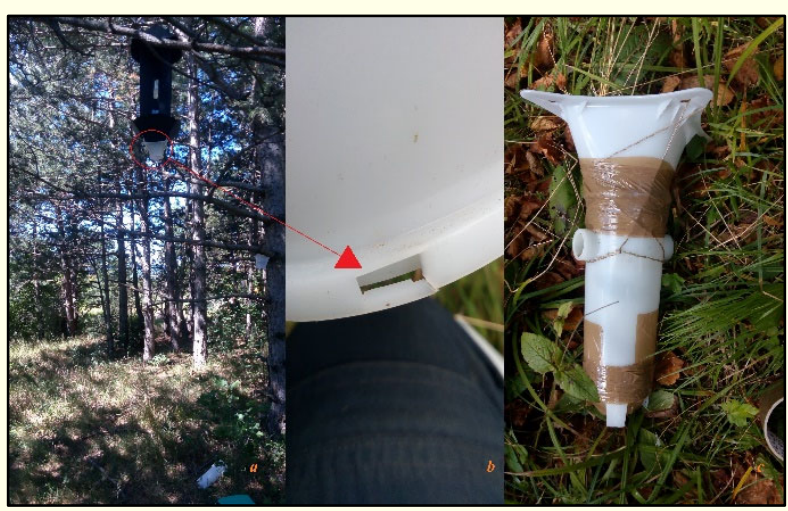

Slika 4: Polomljeni noslici zbirne posode so lahko posledica vandalizma in/ali naravnih dejavnikov (a, b). Lepilni trak in vrvica sta ključna za uspešno improvizacijo na terenu (c) (foto: P. Smolnikar, GIS)

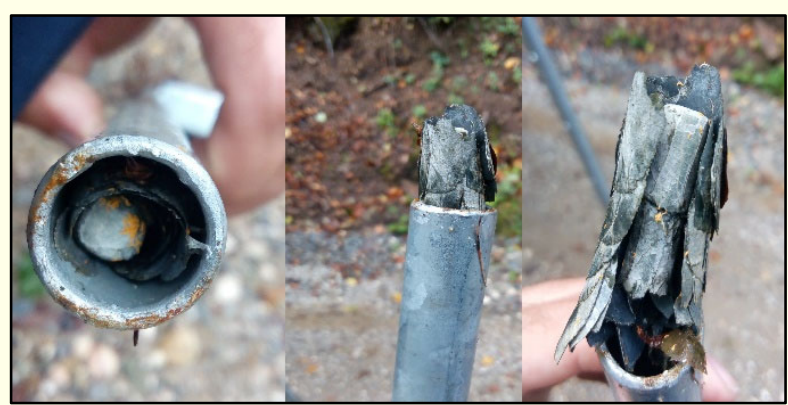

Slika 5: Prevoz slepih potnikov (v konkretni situaciji je sicer nedolžen primer prevoza čebel iz družine znosk (Hymenoptera, Megachilidae)) v votli kovinski konzoli (ogrodju), uporabljeni za namestitev pasti tipa Theysohn. (foto: P. Smolnikar, GIS)

\section{Diskusija in zaključek}

Pri terenskem delu prihaja do neljubih dogodkov, ki so izven naše kontrole, vendar pa se lahko do določene mere tudi pripravimo nanje in njihov vpliv zmanjšamo.

Delo na terenu velikokrat opravljamo sami, zato je pogoj za varno delo polna baterija telefona in izpraven 
avto $\mathrm{s}$ polnim rezervoarjem goriva, še posebej $\mathrm{v}$ primeru, da zaidemo ali obtičimo na gozdni cesti/vlaki ali v zastoju. Pametno je, da pred odhodom na teren svojim sodelavcem in/ali domačim sporočimo lokacijo, kjer se bomo gibali - še posebej, če bomo delo opravljali na bolj odročnih lokacijah. Pred odhodom na teren je pregled vremenske napovedi obvezen - vreme v poletnih mesecih je lahko zelo nestanovitno in zgodi se lahko, da če nekje prečkamo hudournik, se po isti poti ne bo možno tudi vrniti. Neugodno vreme, npr. močno deževje in/ali močan veter, pa lahko tudi popolnoma onemogoči delo na terenu.

Težavo neustrezne lokacije lahko rešimo s tem, da imamo pripravljeno rezervno lokacijo ali še bolje, da imamo sestojno karto naloženo na tabličnem računalniku in na terenu sproti poiščemo drug sestoj z gostiteljskimi drevesi (Slika 6). Na teren tudi vedno nesemo več opreme, kot je zares potrebujemo - dodatna vrv, žica, lepilni trak, vezni trakovi, teleskopska palica in nož ter sekira so ključni pripomočki, ki jih lahko uporabimo za improvizacijo (Slika 4). Dostopnost oz. zaprtost gozdnih cest je z vidika terenskega dela problem, ker lahko onemogoči obisk željene lokacije. Lokacije in trajanje zapor oz. postavljenih zapornic (ramp) niso objavljene, zato bi bila koristna nadgradnja pregledovalnika ZGS z lokacijami zapornic na gozdnih cestah, $\mathrm{z}$ dodanim obveščanjem o začasnih zaporah in kontaktnimi podatki pristojnih oseb.

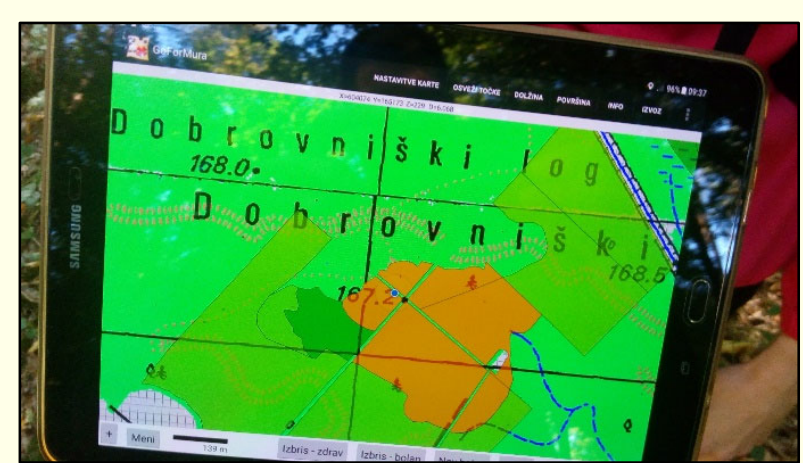

Slika 6: Tablični računalnik z naloženimi zemljevidi, digitalnimi ortofoto posnetki (DOF50), sestojno karto in GPS sistemom je odličen pripomoček za orientacijo in iskanje primernih lokacij kar na terenu samem (foto: P. Smolnikar, GIS)

$\mathrm{Na}$ vandalizem sicer ne moremo vplivati, lahko pa poskrbimo, da kontrolno past postavimo tako, da ni vidna mimoidočim, poleg pa obesimo tudi obvestilo $\mathrm{z}$ informacijo o namenu postavitve, logotipom GIS in kontaktnimi podatki odgovorne osebe. Vsakič, ko obiščmo lokacijo, je dobro imeti s seboj dodatne vabe in pasti za primer odtujitve. Pasti lahko poškodujejo tudi naravni dejavniki, zato jih je dobro predvideti in se izogibati nameščanju pasti na odmrla drevesa ali tik poleg njih. Še posebej na Primorskem je veter lahko zelo močan, tako da pasti v krošnji nihajo z veliko amplitudo in prihaja do izlivanja vsebine zbirne posode ali celo do mehanskih poškodb npr. zaradi udarjanja ob veje (Slika 4), zato je pasti priporočljivo pritrditi z dodatnimi vrvicami. Včasih nam pasti poškodujejo divje živali, zato pasti, če je le možno, postavimo tako, da jih divjad ne doseže oz. se pri postavitvi pasti izogibamo krmišč, solnic ter stečin, kjer je frekvenca pojavljanja divjih živali večja.

Ugotavljanje navzočnosti nekaterih organizmov (npr. Monochamus spp.) poteka skozi celo obdobje aktivnosti odraslih osebkov, kar lahko znaša 5-7 mesecev. Pri nameščanju pasti se izogibamo bližini dreves označenih za posek ali celo namestitvi nanje. Včasih se zgodi, da je kontrolna past nameščena na drevo ali mesto, ki v tekočem letu postane del aktivnega sečišča (žarišče lubadark, vetrolom, redna sečnja, ki ob začetku sezone ni bila predvidena, gradnja dodatne prometnice ipd.). Zato je pomembno, da se o postavitvi pasti na določeni lokaciji posvetujemo z revirnim gozdarjem, ki nas bo v primeru izdaje odločbe ali nenadnih dogodkov pravočasno obvestil o načrtovanih aktivnostih, da bomo lahko past varno odstranili oz. prestavili

$\mathrm{Za}$ zmanjšanje vpliva pozabljivosti in nerodnosti terenskega delavca je najboljše osnovati red. Potrebščine imamo vedno na svojem mestu in pospravljene v preglednem kovčku ali nahrbtniku. Dobro je, če si pripravimo seznam potrebščin za delo na terenu in ga prekontroliramo pred vsakim odhodom na teren.

Na teren, če je le možno, se odpravimo z avtomobilom s pogonom na vsa kolesa (vsaj prvič, ko še ne poznamo prometnic in še iščemo primerno lokacijo). Obtičanju in poškodbam vozila se lahko izognemo, če pred obračanjem in v drugih kritičnih situacijah (npr. vožnja po strmem, neutrjenem, razmočenem in/ali kamnitem terenu ipd.) izstopimo iz avta in pregledamo okolico za morebitne skrite veje, kamne in luknje na mestu, kjer želimo obrniti ali prečkati kritičen odsek prometnice. Situacijo kritično ocenimo in prilagodimo svoje nadaljnje ravnanje. Preden zapustimo avtomobil izklopimo vse porabnike električne energije $\mathrm{v}$ avtomobilu, avtomobilske ključe pa vedno pospravimo v žep z zadrgo, da jih ne izgubimo! Pred prevozom demontiranih pasti vedno preverimo skrita mesta, da ne prevažamo slepih potnikov, tako z vidika naše varnosti (npr. piki insektov), kot tudi biovarnosti (razširjanje organizmov) (Slika 5).

Pogoj za varno izvedbo je tudi psihofizično stanje. Ob vračanju s celodnevnega terena, še posebej iz bolj oddaljenih krajev in v poletni vročini, lahko nenadoma pride do močne utrujenosti za volanom. Če je le možno, je priporočljivo, da na takšne daljše poti hodita dva sodelavca, ki se po potrebi izmenjujeta pri vožnji. Pogoj za uspešno opravljeno nalogo, tako v pisarni in še posebno na terenu, je sposoben sodelavec. Na terenske naloge, kjer potrebujemo dodatno pomoč, se vedno odpravimo $\mathrm{z}$ izkušenim, sposobnim in zaupanja vrednim sodelavcem, s katerim smo dober tim.

\section{Pa srečno!}

\section{Zahvala}

Izvajanje nalog spremljanja karantenskih in drugih škodljivih organizmov, ki jih v slovenskih gozdovih še ni, financira UVHVVR v okviru javnega pooblastila GIS. Pripravo in objavo prispevka je omogočila Javna gozdarska služba GIS (Naloga 2). Zahvaljujem se vsem sodelavcem, ki so kakorkoli prispevali svoja opažanja in težave s terena. Recenzentom pa se zahvaljujem za pregled besedila in konstruktivne komentarje pred objavo. 


\section{Viri}

Delegirana uredba Komisije (EU) 2019/1702 z dne 1. avgusta 2019 o dopolnitvi Uredbe (EU) 2016/2031 Evropskega parlamenta in Sveta z vzpostavitvijo seznama prednostnih škodljivih organizmov. 2019. Ur. 1. EU, št. 2019/1702

Izvedbena uredba Komisije (EU) 2019/2072 z dne 28. novembra 2019 o določitvi enotnih pogojev za izvajanje Uredbe (EU) 2016/2031 Evropskega parlamenta in Sveta, kar zadeva ukrepe varstva pred škodljivimi organizmi rastlin, ter razveljavitvi Uredbe Komisije (ES) št. 690/2008 in spremembi Izvedbene uredbe Komisije (EU) 2018/2019. 2019. Ur. 1. EU, št. 2019/2072

Program preiskav za ugotavljanje navzočnosti škodljivih organizmov rastlin. 2020. Pajk P. (ur.). Ljubljana, Uprava RS za varno hrano veterinarstvo in varstvo rastlin: 348 str.
Uredba (EU) 2016/2031 Evropskega parlamenta in Sveta z dne 26. oktobra 2016 o ukrepih varstva pred škodljivimi organizmi rastlin, spremembi uredb (EU) št. 228/2013, (EU) št. 652/2014 in (EU) št. 1143/2014 Evropskega parlamenta in Sveta ter razveljavitvi direktiv Sveta 69/464/EGS, 74/647/EGS, 93/85/EGS, 98/57/ES, 2000/29/ES, 2006/91/ES in 2007/33/ES. 2016. Ur. 1. EU, št. 2016/2031

* Gozdarski inštitut Slovenije, Večna pot 2, 1000 Ljubljana peter.smolnikar@gozdis.si

Ključne besede: priporočila, programi preiskav, karantenski škodljivi organizmi, kontrolna past, navzočnost 